\title{
Panorama poético de Manuel González Prada
}

\begin{abstract}
A Firma Enrique Anderson Imbert, en la página 186 de su excelente Historia de la literatura hispanoamericana (México, 1954), que "La importancia de González Prada en la literatura hispanoamericana se debe más a su prosa que a sus versos; lo que no significa que sus versos fueran malos, sino que su prosa fué mejor". Sin necesidad de poner en duda la validez de esta aserción, se puede parafrasearta escribiendo que la importancia de González Prada se debe más a su prosa que a su poesía porque aquélla se conoce mucho mejor que ésta, entre los letrados de Hispanoamérica. No han sido numerosas las ediciones de sus prosas y versos; largos años han transcurrido entre una y otra, y el número de ejemplares de cada edición de sus libros (mayor en el caso de la prosa que en el del verso) nunca ha sido grande. Aún quedan por publicarse, según Luis Alberto Sánchez, los dos volúmenes restantes de las Obras completas del gran polígrafo peruano. ${ }^{1}$

Dadas estas circunstancias, y añadido a ellas el hecho de que Adoración, último volumen de la poesía inédita de González Prada, no apareció en Lima hasta mediados de 1947, muy poco debe extrañar el que ningún crítico o historiador literario, que sepamos, haya intentado un examen, por somero que fuere, de toda la lírica pradiana publicada hasta ahora. ${ }^{2}$ Tampoco, creemos, se ha reseñado sucintamente toda la poética existente de González Prada, junto con una exposición compendiosa de sus teorías métricas y unos ejemplos ilustrativos. Este es, por tanto, el propósito de las páginas que siguen.
\end{abstract}




\section{Poeta multiforme}

Grande es la sorpresa del lector que conoce a González Prada sólo como prosista, cuando se ahonda en la lectura de sus versos. La prosa suya, instrumento preciso, poderosamente gráfico y deliberadamente uniforme, tiene el único objeto de galvanizar a un pueblo decaído o de persuadir al lector, sea instruído o lego, de lo justo y razonable que son los postulados del autor. La poesía, en cambio, es multiforme y refleja el ser más íntimo de González Prada en todas sus variadas facetas. Esta verdad se destaca de un modo creciente al estudiar detenidamente los temas, las figuras $y$ las actitudes de sus nueve volúmenes de versos. ${ }^{3}$ Con igual laboriosidad que la que dedica a la composición de su prosa, cultiva el hondo llamado lírico, que escucha toda su vida y que desborda en su alma como una corriente a veces suave y otras abrumadora. Mucho más libre que en su prosa, el espíritu de González Prada logra expresar en sus versos la esencia de sus grandes angustias: sus pretensiones sociales y humanitarias; su visión del mundo, la naturaleza y la vida; las hondas preocupaciones filosóficas que siente a pesar de su creciente negación de la metafísica; su fe en la razón y en la ciencia; su esperanza del porvenir, y aun sus magnos enojos y sus odios minúsculos. Su obra poética es así -mucho más que su prosa- la síntesis del artista y del crítico. En ella están la belleza más preciosa y noble y la angustia dolorosa del hombre de ideas y de acción.

Este polifacetismo poético de Prada refleja, en parte por lo menos, las variadas influencias literarias que recibe a lo largo de su carrera lírica. En su juventud, allá por el 70 , se familiariza con los grandes románticos españoles, ingleses y alemanes, y nacen en el joven silencioso $\mathrm{y}$ arisco un idealismo que sobrevivirá durante toda su vida y una melancolía igualmente perdurable. En el transcurso de los años de su retiro en la hacienda de Mala (1870-1879) recibe, como contrapeso a este romanticismo, su inoculación de realismo humanitario. Lee a los humoristas españoles y franceses, los poetas paganos como Khayam, y los brillantes prosistas de la Europa contemporánea. Se despiertan en él, a raíz de estas lecturas; un amor por la sida y la naturaleza y un cariño por la forma ar- 
tística y la ironia. De poeta metafísico y tenue se convierte en vate dotado de gran poder expresivo por lo objetivo y, sobre todo, por lo peruano. Bien le caracteriza Carlos García Prada en esta época:

González Prada [es] personal y versátil: a veces suspira muy quedo, como Bécquer y Bartrina, y otras sonríe como Heine, Voltaire, Quevedo y Campoamor; a veces su fantasía persigue brumosas lejanías, como Schiller y Uhland, y otras se fija en lo claro y cercano, deleite de Khayam y Meleagro; en ocasiones se refugia en su torre de marfil, y en otras, desciende a la palestra pública por acercarse al pueblo $\mathrm{y}$ dirigirlo hacia metas deseables de bien $\mathrm{y}$ de justicia. Es una nave "que no iza bandera en sus mástiles" y navega a su capricho "en el mar de los libres". 4

En las temporadas de ocio durante sus años campestres o su residencia en París (1891-1895), lejos del tumulto mundano, busca solitario el consuelo divino de la poesía. Extático espectador panteísta de la naturaleza, siente el irreprimible empuje lírico brotar en él y canta suavemente "el misterioso ritmo de los seres y las cosas". Y cuando varie de tema, será para celebrar en formas estróficas insólitas: laudes, rispettos, estornelos, espenserinas y balatas, al amor a la mujer, o al arte desnudo y divino de los griegos.

En las horas de lucha, sin embargo, sus iras y odios se expresan - cuando abandona la prosa- en hirientes versos cortos, gráficos y punzantes. Ya no es el fino y sensual amante de la soledad, habitante de la torre ebúrnea, sino el vate en acción, el profeta que encabeza la multitud, denunciando toda flaqueza, todo vicio humanos y reclamando la justicia, el amor y la comprensión mutua entre los hombres.

La figura de González Prada, poeta en el Perú, por común acuerdo de los críticos, es señalada como el punto de origen de la poesía nueva; de la poesía que, emancipándose del colonialismo, logra desarrollar un legítimo carácter nacional y viene a dar en la poesía pura contemporánea. Observa Sebastián Salazar Bondy que en Prada, a pesar de nutrirsa éste en las fuentes del positivismo francés y ser rendido raciopalista, "se descubren, para su dispensa, francos deseos de liberar a la poesía peruana de su estruendo y de su característica elocuencia vacía, en esfuerzo por dotarla, morigerados sus tradicionales atributos retóricos y dentro equilibradas formas de brío parnasiano, de una médula intima de 
auténtica inspiración". "Otra faceta de su empeño renovador es el intento de ensayar una poesía inspirada en el almá aborígen; esfuerzo que más tarde llegará a su fruición en los poetas y autores indigenistas nacionales. Entre los poetas que le siguen de cerca, sobre todo en el caso de José Santos Chocano, se nota la influencia del aspecto renovador de Prada junto con el efecto de su pertinaz romanticismo. Así Chocano, primer modernista peruano, nunca logra dejar atrás su parentesco romántico, y las baladas indígenas de González Prada, temerosas y plañideras, en Chocano devienen orondas y recargadas, distando mucho de reflejar la verdad íntima del sobrio espíritu incaico. Desgraciadamente, la poesia de Chocano gana discípulos y admiradores y durante largo tiempo domina en el reducido mundo literario peruano, imposibilitando el cultivo con éxito del otro tipo de creación poética señalado por González Prada, o sea el lirismo íntimo y artístico.

\section{Sus obras poéticas}

Para la mejor comprensión del desenvolvimiento de González Prada como poeta y para dar al lector una idea deh aspecto cronológico de su producción, dedicaremos un comentario suscinto a cada uno de los nueve volúmenes de sus versos publicados hasta la fecha. La cronologia precisa de sus poemas presenta un problema dificil, a veces insoluble, pues, a pesar de la paciente labor editorial de su hijo Alfredo al preparar las sucesivas ediciones póstumas, hay muchas poesías cuya fecha de composición se ignora.

1. Baladas peruanas. Recoge este volumen (primera edición, 1935) los poemas que González Prada compone entre 1871-1879, cuando goza en el campo de Mala el único largo trecho sosegado de toda su vida. Con este libro se inicia en el Perú la verdadera poesía indigenista y en él canta el autor, en sencillos octosílabos divididos en cuartetos, el indio prehispánico y el indio sufriente después de la conquista. En las Baladas el indio no es decoración romántica ni objeto de elegías falaces, sino un ser real que vive su tragedia y logra a veces su venganza contra los blancos. Hay, asimismo, excelentes interpretaciones poéticas de la naturaleza y una comunicación del sentido más íntimo del paisaje andino.

2. Minúsculas. Corto volumen que recoge muestras de lo más sutil, aristocrático y frágil de su obra poética entre 1869 y 1900 (primera edición, 1901). 
Temas : amor, naturaleza, melancolía, alegría, paganismo, panteísmo; actitud: parnasiana; forma: metros nuevos (triolet, rondel, rispetto, espenserina, etc.). En lo que el libro manifiesta de la experiencia europea y del cosmopolitismo de González Prada, y en sus novedades formales, está la base de las pretensiones del poeta como precursor del modernismo. Libro exquisito que introduce la semilla de la poesía pura en la literatura peruana.

3. Grafitos. (Compuesto entre 1866 y 1918, primera edición, 1937). "Grafito", nombre dado por el propio poeta y tomado de la voz griega graffitio, significa epigrama o caricatura espontánea. En ellos el poeta hace alarde de su talento crítico-pictórico y, variando entre el humor inocuo y la sátira mordaz, comenta concisamente temas de hombres, mujeres, amor, viajes, religión, moral y política.

4. Baladas. (Compuesto entre 1871 y 1914?, primera edición, 1939.) Junta este libro traducciones juveniles de González Prada de poetas alemanes, franceses e italianos, algunas imitaciones de los poetas traducidos y las composiciones originales del peruano (que constituyen la mayor parte). Las traducciones e imitaciones dan una idea de su dominio de lenguas, su poder asimilativo y su preferencia por los temas germanos, escandinavos, ingleses e italianos, y demuestran, a la vez, su cariño por los antiguos romances españoles. Las composiciones originales atestiguan el poder de su talento poético, que logra dejar un cuño personal en una forma que no le es nativa.

5. Adoración. Los versos coleccionados en este libro, nacidos de los amores de Manuel y Adriana de Verneuil (con quien se casó en 1887), fueron compuestos entre 1884 y 1885 pero quedaron inéditos hasta 1947. El autor quiso que se titularan Corona de Adriana; ésta Adoración. De carácter confidencial y propósito muy personal, estos poemas amorosos no ostentan el pulimento dilatado que sufre la mayor parte de su poesía. En cambio, poseen una sinceridad que brota claramente del corazón amante de Manuel y logra transmitir sin equivocación sus más íntimos impulsos. El libro demuestra, además, el empleo frecuente de innovaciones estróficas como el rondel y el triolet.

6. Presbiterianas. Poesías anticlericales, a veces de una implacable furia corrosiva, que expresan el racionalismo arraigado del poeta y reflejan, a la vez, la melancolía que es producto de su incredulidad desesperanzada. Compuestas entre 187? y 189?, su primera y única edición es la anónima de 1909.

7. Exóticas. Volumen que sigue la linea innovadora de Minúsculas y en en el cual culmina la virtuosidad poética de González Prada. Escritas estas poesías, en su inmensa mayoría, durante su residencia en París, la primera edición del libro no se publica hasta 1911. En Exóticas aparecen el romántico, el parnasiano, el pagano clásico y el precursor del modernismo. Hay, además, todos los metros novedosos de Minúsculas y algunos nuevos, como el verso 
libre. A Exóticas perteneoe, por otra parte, una de sus pocas composiciones en que emplea el simbolismo: "Los caballos blancos". Y las Notas del libro añaden mucho de valor a nuestro conocimiento de las teorías poéticas del autor.

8. Libertarias. Poemas cortos de crítica social y política, semejantes en su intención a muchos grafitos o a los versos de Presbiterianas. Aparecieron sin firma o con pseudónimos, de 1904 a 1909, en Los Parias, periódico radical limeño. La primera edición en volumen es de 1938.

9. Trozos de vida. (Compuestos en 1918, primera edición, 1933.) Escritas las ciento cincuenta poesías breves durante sus últimos seis meses, cuando González Prada vive bajo la posibilidad de una muerte inminente, nos dan la trayectoria psíquica de sus postreros días. De un tono lírico alto pero nivelado, la tristeza metafísica de la primera parte del libro alterna con los arranques de regocijo de la segunda, cuando el poeta recuerda sus comuniones con la naturaleza o evoca el amor feliz que ha sosegado su vida. Las breves estrofas de ocho versos octosílabos, suaves, sencillas, transparentes, resumen el mensaje de despedida del poeta: más que la muerte puede el recuerdo del amor, y sobre el amor, están la razón y el deseo de perfecccionamiento ético del hombre del futuro, quien sabrá construir una vida mejor.

\section{Concepto de la poesia}

Como en el caso de sus ideas sobre la literatura y la prosa, González Prada expresa opiniones claras y firmes acerca de la poesía. Pero el prosista que lleva sus teorías genialmente a la práctica es un poeta que no siempre se acomoda a la fórmula que enuncia. El positivista que raciocina irreprochablemente en sus ensayos y discursos deviene un poeta de suave y melancólico lirismo, y en el proceso descubre la fachada falsa - resultado de su reputación de prosista- tras la cual se ha escondido un alma de exquisita sensibilidad. Proclama que la poesía del porvenir será "el canto de la Razón", " pero es otro el canto de sus versos; recomienda a los poetas inspirarse en el "maravilloso positivo" de la ciencia, y busca él su numen en la negación, la duda o "el misterioso ritmo de los seres y las $\operatorname{cosas}^{\prime \prime} ;^{\top} \mathrm{y}$, por fin, denuncia como defecto de los modernos poetas "el no entrar de lleno en la corriente del siglo", 8 mientras que él mismo prueba alimentarse de sustancias helénicas.

De las varias definiciones o descripciones que hace de la poesía, se destaca un concepto general y básico: que la poesía, como 
la prosa, es una fase del "supremo poder intelectual", o la facultad de comunicar sencilla y claramente las verdades más profundas y elevadas. La radical diferencia entre la prosa y el verso, según González Prada, está en el indispensable elemento del ritmo que éste debe poseer. ${ }^{9} \mathrm{La}$ poesía, "desdeñando las onomatopeyas y todas las demás puerilidades seniles, armoniza el ritmo de la palabra con el ritmo silencioso de la idea..." 10 Grave y difícil es la tarea del poeta: debe sentir, pensar y progresar, manteniéndose siempre a la altura de su tiempo. "El poeta será didáctico, no para vulgarizar las leyes particulares de una ciencia, sino para enunciar por medio del ritmo y de la imagen las conclusiones generales del saber humano. El cantor digno de su época, sube a lo más elevado para anunciar hasta dónde llegaron los hombres en la ascensión a la verdad. Arroja un puente de luz a la oscuridad". ${ }^{11}$ En cuanto a la forma del verso, recomienda que se evite en él las "amplificaciones inútiles i vacías" y que sirva para "expresar las ideas en forma concisa... i lapidaria" 12 (recomendaciones que el mismo autor adopta instintivamente).

A pesar de recalcar tanto el elemento racional en la poesía y negar la posibilidad del papel de la intuición en la creación artística, ${ }^{13}$ González Prada no escatima una consideración del necesario elemento espontáneo y lírico de la poesía. Hace, en verdad, una defensa elocuente del lirismo. Entabla una conversación imaginaria y contesta a un supuesto hombre de negocios que, al ver un nuevo libro de poesia, ha exclamado:

- Cómo! ¿Todavía imprimen versos?

- Sí, modernas encarnaciones del eterno Sancho, aun se publican versos porque hay poesía; y habrá poesía mientras los astros no queden sustituidos por faroles chinescos, mientras los mirtos no produzcan legumbres, mientras los ruiseñores no salmodien el de profundis, mientras los niños nazcan sin arrugas ni canas, mientras el árbol de la Humanidad produzca la divina flor de la belleza". 14

Cree, con Shakespeare, que los hombres encierran en "el corazón del corazón" a los poetas y los llama "los ilusos incurables o niños eternos que saben sentir y comunicar el aroma del sentimiento". $\mathrm{Y}$ hablando de las obras literarias, sobre todo de la poesía, dice que: "son polvo; mas el polvo, amasado con lágrimas, se cristaliza, se transforma en diamante. Este impenetrable corazón del hom- 
bre parece una esponja humedecida con escasa porción de almíbar: se necesita estrujarla con toda fuerza para hacerla destilar unas cuantas gotas de dulzura". ${ }^{15}$

\section{Teoría de la versificación}

Espiritu innovador, siempre en busca de modos nuevos, creyente en la evolución y el progreso, González Prada censura la tradicional ampulosidad y la carencia de ideas que imputa a la moderna poesía hispánica:

Atronadora y rimbombante Poesía castellana, Tambor mayor en la orquesta de Píndaro y Homero, Si poco arrullas a las almas, mucho asordas los oídos.

En el espeso follaje de inútiles vocablos, Brota pálida y sin jugo la fruta de la idea. iOh verbo de Cervantes, en tu viña empampanada Son gigantescas las hojas, enanos los racimos! 16

También le fastidian la forma externa de esta poesía, su monotonía prosódica y su pobreza rítmica. Observa que "Los modernos poetas castellanos no se han mostrado muy fecundos en la invención de ritmos ni de estrofas: así que nuestro arsenal métrico permanece casi el mismo desde los tiempos de Boscán y Garcilaso. Fuera de Iriarte en sus fábulas, casi nadie salió de la rutina". ${ }^{17}$ Cree que poetas como Campoamor, Núñez de Arce, Espronceda, Zorrilla y la Avellaneda han sido muy tímidos en sus esfuerzos de aclimatar nuevos metros o rejuvenecer los antiguos y desusados. ${ }^{18}$

Tampoco los preceptistas se han salido del hábito, pues "casi no hubo ninguno que abandonara las huellas de Nebrija y del Pinciano, ni que olvidara la manía de buscar en nuestro idioma dáctilos o anapestos, yambos o troqueos..." Señala como excepción sólo una figura, el "erudito catalán, don Sinibaldo de Mas, [que] salió del camino trillado y quiso abrir nuevos senderos a la versificación española, aunque también cayó a veces en la manía de fundar una versificación basada en las sílabas largas y las breves. Don Edurdo Benot, en los tres formidables y amenazadores volúmenes de su Prosodia castellana y versificación, no consigue más que embrollarlo todo, sin enunciar una clara teoria del ritmo". Re- 
sume su juicio del tema con una afirmación que más tarde desarrollará con mayor amplitud: "Así, después de miles y miles de versos escritos por sudamericanos y españoles se debe asegurar que el ritmo castellano está por enriquecerse y hasta por fijarse; después de numerosas poéticas dadas a luz en España y Sudamérica se puede afirmar aun con Menéndez y Pelayo que la verdadera métrica de nuestro idioma está por hacerse". ${ }^{19}$

Carlos García Prada, al comentar las ideas de González Prada acerca de la versificación castellana, opina que el peruano habla con razón y conocimiento de causa". Pasando revista a los más notables preceptistas españoles (inclusive a Cejador y Frauca) y al venezolano Andrés Bello, García Prada concluye que: 1) éstos están "todos acostumbrados al estudio del verso castellano sobre ilusorias bases de conocimientos teóricos y mecanísticos, ajenos por completo al análisis experimental y a la psicología de la belleza y del ritmo"; y que 2) "en realidad, lo dicho por estos preceptistas es empírico e inadecuado, y ni explica satisfactoriamente la estructura estética del verso castellano, ni sirve para mucho en manos de artistas originales y seguros." 20

La teoría de González Prada, ya vislumbrada en su insistencia en que la creación lírica del poeta se exprese armoniosamente ("todo el arte del poeta consiste en vestir de púrpura la verdad i hacerla moverse a compás del ritmo"), ${ }^{21}$ se enuncia definitivamente en 1911, en las Notas de la primera edición de Exóticas. Resumimos sus nociones teóricas a continuación, a fin de que se conozca en detalle el valor positivo de sus innovaciones en la métrica castellana.

Negando, caracteristicamente, las leyes tradicionales de los preceptistas y prescindiendo de toda nomenclatura clásica, González Prada afirma que "las sílabas acentuadas y no acentuadas de nuestro idioma ninguna semejanza tienen con las largas y las breves de la lengua latina". Por tanto, donde "la métrica latina se basaba en las combinaciones de largas y breves", la versificación castellana "se funda en el acento". $Y$ continúa: "No cabe negar que poseamos sílabas largas y sílabas breves; pero, al tratarse de versificación, hemos convenido en establecer el isocronismo de las silabas, reconociendo que su diferenciación estriba únicamente en el acento." Fija, así, no la sílaba, sino el "tiempo", como unidad métrica en 
el lenguaje artístico, sea poesía o prosa. En este principio - tan bien ejemplificado después en la producción de escritores artísticosbasa su teoría del ritmo. En el español, declara "No poseemos Métrica sino Rítmica."

El tiempo o elemento rítmico consta de "una sílaba acentuada o tónica, seguida o precedida por sílabas no acentuadas o átonas". Hay elementos descendentes cuando la tónica precede $\mathrm{y}$ ascendentes cuando sigue. Tales elementos rítmicos en el castellano se resumen así:

a) dos elementos binarios, ascendente y descendente, oó y óo;

b) dos elementos ternarios, ascendente y descendente, ooó y óoo, $\mathrm{y}$

c) dos elementos cuaternarios, oooó y óooo.

Los elementos quinarios, sextarios y heptarios, observa González Prada, "entran como elementos disonantes".

Después de explicar su teoría el peruano pasa a considerar el ritmo verbal que produce "la sucesión melódica de elementos rítmicos". Sugiere, pues no está seguro de acertar, una división del ritmo en "perfecto", "proporcional", "mixto" y "disonante". En el perfecto (también lo llama "continuo") se repite el mismo elemento rítmico, sea binario, ternario, etc.: oóloó/oó/...; ooó/ooól ooó/...; 000ó/000ó/000ó/...; o óo/óo/óo/...; óoo/óoo/óoo, etc. En el proporcional se suceden y alternan libremente los elementos binarios y cuaternarios, con exclusión de los demás: oó/oó/oooó/oó, oooó/oó/oó/oó..., etc. En el mixto dos o más elementos de clase diferente: oó/oó/ooó/ooó/..., ooó/ooó/oó/oó/..., etc. Y en el disonante una serie del mismo elemento va precedida, cortada o rematada por un elemento diferente, produciéndose así una disonancia inicial, intermedia o final: oó/ooó/ooó/ooó/...; óo/óoo/óo/ óo/...; oob/ooó/ooó/00oó/... Dado el aspecto matemático de su teoría, es obvio que en cada verso existe la posibilidad ilimitada de combinaciones variadas y, en las estrofas o en el poema, de armonías simples o complejas.

El valor de la teoría nos parece indiscutible: es sencilla, está claramente expresada y se presta a la composición de efectos melodiosos y armoniosos en el verso, la estrofa o el poema. Constituye, además, un progreso notorio en el dominio bastante desatendido de la prosodia española. ${ }^{22}$ 


\section{Innovaciones métricas}

Al antiguo repertorio prosódico castellano, González Prada, animado por hondos impulsos proteicos, trae nuevas estrofas del francés, del inglés y del italiano para adaptarlas al español. Inventa otras por cuenta propia. Sus innovaciones no terminan aquí; trata, además, de transformar el verso mismo. Antes que Rubén Darío, intenta resucitar el verso eneasílabo (empleado por los antiguos poetas españoles populares en refranes, glosas y canciones); cultiva el endecasílabo de acentos en la tercera, séptima y décima sílabas (novedad practicada más tarde por los modernistas); compone poemas enteros en versos de metros alkmánicos (óoo/óoo...) antes que Darío intentara sus hexámetros; y da un gran impulso en el español al desenvolvimiento del verso libre, cultivado por Whitman en los Estados Unidos y por Baudelaire y otros simbolistas franceses. ${ }^{23}$

Interesa ahora considerar las importaciones e invenciones métricas que constituyen una parte tan grande de sus contribuciones a la poética del mundo hispano.

RONDEL. Forma corta, delicada, adaptada de modelos franceses medievales y renacentistas, que en González Prada encuentra tres patrones usuales: rondel, triolet y villanela. El triolet, la más sencilla y exquisita, tiene ocho versos, que pueden ser de ocho a doce sílabas con sólo dos rimas, repitiéndose el primer verso en forma de ritornello al medio y al fin del poema, abaaabab. El rondel contiene ordinariamente quince endecasilabos en tres estrofas (la primera de cinco, la segunda de cuatro y la tercera de seis) y sigue varios esquemas rítmicos. Comúnmente los versos finales de la segunda y tercera estrofas son un bordoncillo de siete sílabas. Hay, sin embargo, algunas otras variaciones de verso y rima. La villanela consta de un número indefinido de tercetos octosílabos con rima $a b a$ en todas las estancias, y que termina con un cuarteto $a b a b$.

TRIOLET

Desde el instante del nacer, soñamos;

Y sólo despertamos, si morimos.

Entre visiones y fantasmas vamos:

Desde el instante del nacer, soñamos. 
El bien seguro, por el mal dejamos;

$Y$ hambrientos de vivir, jamás vivimos:

Desde el instante del nacer, soñamos;

$\mathrm{Y}$ sólo despertamos, si morimos.

ESPENSERINA. Estrofa cambiante que González Prada adapta de la forma inventada por Edmund Spenser en su largo poema The Faerie Queen y cultivada por otros poetas ingleses. En la poesía del peruano es una estrofa de ocho endecasílabos finalizada por un verso de trece sílabas y que rima así : $a b a b b c b c c$. Ejemplo:

Pide a las aves desdeñar el nido, Pide a los campos rechazar el riego; Mas nunca pidas desamor ni olvido, A un corazón enamorado y ciego.

Haz de las nieves irradiar el fuego, Detén el huracán en su carrera, Infunde al mar la calma y el sosiego, $\mathrm{Y}$ rige el Sol en la inviolada esfera, Si quieres tú que yo te olvide y no te quiera.

RISPeTto. Poesía monoestrófica de asunto amoroso, cultivado con singular éxito por González Prada. Consta de ocho endecasílabos rematados por dos o más versos para adaptarlos mejor al baile. El esquema de rimas es ababccddee. Ejemplo:

Era la noche: en lóbrega laguna Agonizaba el resplandor de Sirio, Mientras rayaba en el zenit la Luna, Con la enfermiza palidez de un cirio. Pensé mirar de lejos tu belleza, $\mathrm{Y}$ suspiré de amor $\mathrm{y}$ de tristeza. ¿Por qué no respondiste a mi llamada, En esa noche triste y desolada? ¿Por qué a brindarme amparo no viniste, En esa noche desolada y triste?

balata. Alegre, gracioso y elegante poema parecido al rondel, que llegó antiguamente al español procedente del italiano, para luego caer en el olvido. Cuando González Prada la introduce de nuevo al castellano, estudia los modelos italianos. Consta de tres estrofas de endecasílabos cuya rima es $a b b / c d c d / d b b$. Ejemplo: 
De cuantos bienes atesora el mundo

El bien supremo, el de mayor grandeza,

Emana de tus formas, oh Belleza.

¡Poder! ¿Qué vale dominar al hombre?

¡Oro! ¿No mancha corazón y mano?

¡Gloria! ¿Sabemos si es vacio nombre?

¡Nobleza! ¿Torna en águila al gusano?

Todo a mis ojos aparece vano;

Yo sólo admiro, oh gran Naturaleza,

El ritmo de las formas - la Belleza.

ESTORNELO. De origen toscano, es un poema brevísimo, senci1 lo y expresivo. Generalmente consta de un heptasílabo y dos endecasílabos, aba. Ejemplos:

Blanca Azucena,

Cuando pasar la mires a tu lado,

Dila que ciego voy de enamorado.

No busques, oh Violeta,

Las sombras del follaje: con tu aroma

Denuncias tu morada más secreta.

Luna ¿Qué triste vas y silenciosa!

Así con rayo silencioso y triste,

Alumbrarảs mi șolitaria losa.

Pantum. Imitación directa hecha por González Prada de la forma clásica del pantum, poema de origen malayo, usado por Baudelaire en su Harmonie $d u$ soir. Compónese de cuatro cuartetos endecasílabos con rima $a b a b / b c b c / c d c d / d a d a$. A veces González Prada compone un pantum sin rima. Ejemplo:

\section{PANTUM}

Alzando el himno triunfal de la vida, Muge el torrente en los fértiles llanos;

Yo siento mi alma de júbilo henchida;

Viendo en las mieses cuajarse los granos.

Muge el torrente: en los fértiles llanos.

Templa la sed ardorosa del trigo; 
Viendo en las mieses cuajarse los granos, Yo al sembrador de la tierra bendigo.

Templa la sed ardorosa del trigo, Huye, y al mar el torrente se lanza; Yo al sembrador de la tierra bendigo, Yo me estremezco de amor y esperanza.

Huye, y al mar el torrente se lanza, Dando a las mieses un iay! de partida; Yo me estremezco de amor y esperanza, Alzando el himno triunfal de la vida.

LAude. Poema probab!emente inventado por González Prada, inspirándose al parecer en las laudas y otras composiciones italianas no devotas, del Renacimiento. Son de diez versos octosílabo's. que riman $a a / b b b a / c c c a$. Ejemplo:

Celebremos al arior

Como rey y gran señor.

A torrentes manan dél

Toda luz y toda miel.

En sus labios toda hiel

$\mathrm{Da}$ dulcísimo sabor

En la hoguera del sentir

Consumamos el vivir,

Pues se goza con morir,

$\mathrm{Si}$ se muere nor amor.

CUARTETo PERSA. Estrofa sobria y elegante, que importó González Prada del Oriente. Los versos pueden tener un número diferente de sílabas (endecasílabos, alejandrinos, encasílabos) o un rúmero igual (octosílabos, endecasílabos o quince silabas). La rima es siempre aaba. Ejemplos:

Orgullo con las frentes orgullosas, Bondad con las entrañas bondadosas:

Esa la ley constante de mi vida;

Sólo me inclino a recoger las rosas.

Rendi mi corazón a la belleza, Mas ni el oro acaté ni la grandeza. Limpios están mis labios y mi pluma De vil adulación y de bajeza. 
El rítmico vuelo de la estrofa alada

$\mathrm{Y}$ el rayo de ardiente, pasional mirada,

Encierran lo bello, lo mejor del mundo.

iAmor! ¡Poesía!... Lo restante inada!

No escuches el glacial consejo

De inválido Catón añejo.

La vida de los mozos vive

$\mathrm{Y}$ deja la vejez al viejo.

Gacela. Nombre dado por González Prada a una forma poemática de su propia invención. Tiene, generalmente, doce versos endecasílabos o dodecasílabos y el esquema rítmico aaoaoaoaoaoa, siendo los versos impares, comenzando con la tercera, versos sueltos. Ejemplo:

¡Ay del que sueña sueños de ternura

$Y$ su esperanza cifra y su ventura

En unos ojos de azulado cielo

$Y$ en una tez de virginal frescura!

Suceden siglos de aflicción y pena

A rápidos instantes de dulzura,

Que no hay amor sin tempestàd ni eclipse,

Que unidas van mudanza y hermosura.

Nadie firmeza jure ni demande:

No bien la boca enamorada jura

Que el pájaro siniestro del olvido

Envuelve al hombre con el ala oscura.

POLIRRITMO SIN RIMA. De todas las formas poemáticas inventa. das por nuestro poeta ésta es, sin duda alguna, la más original e interesante $\mathrm{y}$ de mayor riqueza y variedad armónicas. No es propiamente una estrofa, pero sí posee una clara unidad funcional. Es una sucesión de versos independientes, unas veces formados por elementos rítmicos "perfectos" y "proporcionales" y otras, por elementos rítmicos "perfectos", "mixtos" y "proporcionales" - interrumpidos con frecuencia, en el segundo caso, por elementos rítmicos "disonantes" iniciales, intermedios o finales. Ejemplos:

LA DIVINA PODRE

¿Qué fueron las carnes gloriosas de Frine?

$¿ Q$ Qué las rosadas, las frescas, 
Las tentadoras carnes de Rubens? ¿Qué son, oh mujeres, las mórbidas carnes Que locos mordemos y locos besamos? Envolturas de podre forrando un esqueleto.

Mas ique todas las lenguas,

En todos los idiomas,

Te glorifiquen $\mathrm{y}$ veneren,

Oh carne femenina!

¿Que todas las flores te cubran!

iQue todas las liras te canten!

iQue todos los perfumes te perfumen!

iQue todas las coronas te coronen!

¿Que la Tierra y las lunas y los soles te bendigan!

¿Que por los siglos de los siglos, eternamente,

Amada seas, oh divina podre!

$$
\begin{aligned}
& \text { LA DUDA } \\
& \text { OOó/OOÓ/Ooó/00ó/O0ó... }
\end{aligned}
$$

A mis ojos el mar, a mis plantas la arena. Se esfuman en oro de nimbos arcaicos las nieblas de plata, y azula los montes el Sol matutino. Velada mujer misteriosa -i Partamos! - me dice. Con mano de hierro me coge la mano, me arrastra, me empuja a la nave. - ¿Quién eres? pregunto. Si hermosa, te sigo por islas y golfos, en calma y tormenta, por años y siglos. El velo replega: divina hermosura - la Helena de Paris, la Venus de Milo. - $-\mathrm{T}$ u nombre?- Me llamo la Duda, la fiel compañera del sabio, la vista del ciego, la fuerza del débil. La Fe me proscribe, la Ciencia me aclama - ¡Partamos, partamos! ¡Gloriosa la vida vivida contigo! [Dichosa la muerte venida por ti!

$$
\begin{gathered}
\text { RoBert G. MEAD, JR., } \\
\text { University of Connecticut. }
\end{gathered}
$$

$$
\mathrm{N} O \mathrm{TAS}
$$

1 "Las obras completas de González Prada", Hispania, xxxv, (1952), p. 333.

2 Entre los estudios sobre la poesía de González Prada publicados a partir de 1948 se destacan los siguientes: Luis Monguió, La poesía postmodernista peruana (México, 1954), pp. 11-13 y passim; Max Henríquez Ureña, Breve historia del modernismo, (México, 1954), pp. 329-331; Luis Alberto Sán- 
chez, "González Prada, olvidado precursor del Modernismo", Cuadernos Americanos, XII, núm. 6 (Nov.-Dic. de 1953), pp. 225-234; Concha Meléndez, "La poética de González Prada", Asomante, iv, núm. 4 (Oct.-Dic. de 1948), pp. 7277; y José Jiménez Borja, "La poesía de González Prada", Letras, (Lima), 1948, núm. 39, pp. 5-20.

3 Acertadísima nos parece la siguiente observación de su finado hijo Alfredo: "escondía González-Prada delicadezas de artífice y refinamientos de aristócrata ingénitamente en riña con la deliberada altisonancia de ciertos instantes de su estilo [en prosa] ... Pero queremos ... marcar... una diferencia...: la prosa es invariablemente utilitaria, y persigue un fin de crítica social, filosófica, política, religiosa o literaria; la poesía suele no tener otro designio que el Arte por el Arte. $\mathrm{Y}$ de esta divergencia de propósitos, nacen profundas disparidades de forma entre una y otra". Redes para captar la nube, Lima, 1946, pp. 202-203.

4 Antologia paética de González Prada, México, 1940, p. xxviii.

5. La poesía contemporánea del Perú, Lima, 1946, I, p. 7.

6 Nuevas páginas libres, Santiago de Chile, 1937, p. 67.

7 Trozos de vida, Lima, 1948, p. 42.

8 Nuevas páginas libres, p. 65.

9 Páginas libres, Lima, 1946, p. 237.

10 Nuevas páginas libres, p. 76.

11 Ibid., PP. 74-75; El tonel de Diógenes, México, 1945, p. 159.

12 Pájinas libres, loc. cit. Reproducimos la ortografía reformada empleada por González Prada en estos años.

13 Anarquia, Santiago de Chile, 1940, p. 18.

14 Nuevas páginas libres, p. 96.

15 Ibid, pp. 218-220.

16 "Musa helénica", Exóticas, Lima, 1948, p. 41.

17 Nuevas páginas libres, p. 201.

18 Ibid., p. 202.

19 Ibid., p. 203.

20 Antología poética de González Prada, México, 1940, pp. xxxiv-xxxv.

21 Pájinas libres, p. 34. 
22 El crítico dominicano, Pedro Henríquez Ureña, al analizar el rôle de González Prada en la poesía castellana, afirma rotundamente "No other poet has undertaken such a variety of experimerits in "Spanish", (Literary Currents in Hispanic America, Cambridge, 1945, p. 155), y su hermano Max, al insistir en la labor valiosa que González Prada realizó dentro del verso castellano, lamenta la poca atención que han merecido sus innovaciones de los preceptores literarios. (El ocaso del dogmatismo literario, La Habana, 1919, p. 22.)

Carlos García Prada admite las "grandes posibilidades" de la teoría de González Prada pero nota, sin embargo, su empirismo y la considera incompleta "no sólo por cuanto excluye la existencia (comprobada en la práctica por los poetas cultos y por los populares, y también en los laboratorios) de movimientos rítmicos independientes, que no 'disonantes', de cinco, de seis y aun de siete unidades, en la poesía, en la música y en los bailes españoles de ciertas regiones, sino por cuanto no explica el origen, la naturaleza ni la expresividad del ritmo..." (Op. cit., p. xxxvir.)

23 La mayor parte de las ideas de González Prada sobre teoría poética, aparte de las "Notas" de Exóticas, está en las secciones cuarta y quinta de Nuevas páginas libres, pp. 149-254. 